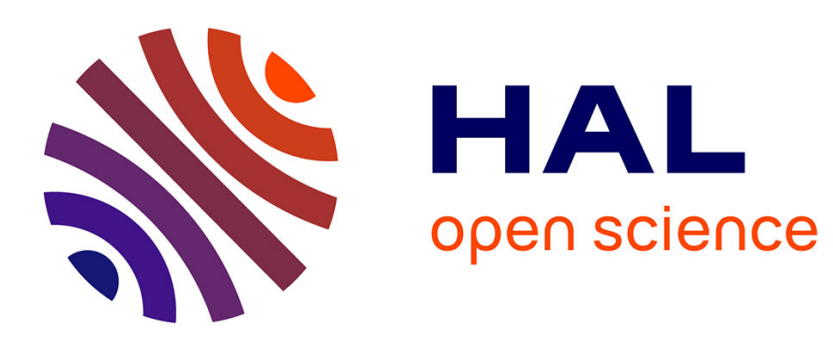

\title{
Viewpoints for Requirement Engineering in a Cooperatif Information System (VpCIS)
}

Kahina Kessi, Mourad Oussalah, Zaia Alimazighi

\section{To cite this version:}

Kahina Kessi, Mourad Oussalah, Zaia Alimazighi. Viewpoints for Requirement Engineering in a Cooperatif Information System (VpCIS). New perspectives in Informations systems Vol 1, pp.299 308, 2014, 10.1007/978-3-319-05951-8_29. hal-01075554

\section{HAL Id: hal-01075554 https://hal.science/hal-01075554}

Submitted on 18 Oct 2014

HAL is a multi-disciplinary open access archive for the deposit and dissemination of scientific research documents, whether they are published or not. The documents may come from teaching and research institutions in France or abroad, or from public or private research centers.
L'archive ouverte pluridisciplinaire HAL, est destinée au dépôt et à la diffusion de documents scientifiques de niveau recherche, publiés ou non, émanant des établissements d'enseignement et de recherche français ou étrangers, des laboratoires publics ou privés. 


\title{
Viewpoints for Requirement Engineering in a Cooperatif Information System (VpCIS)
}

\author{
Kahina Kessi ${ }^{1}$, Mourad Oussalah ${ }^{2}$, and Zaia Alimazighi ${ }^{1}$ \\ ${ }^{1}$ LSI-FEI-USTHB Computer Science Department BP 32 El-Alia Beb-Ezzouar, Alger 16111 \\ ${ }^{2}$ LINA-Nantes University Computer Science, Nantes, France \\ \{kkessi,zalimazighi\}@usthb.dz, Mourad.Oussalah@univ-nantes.fr
}

\begin{abstract}
In this paper we propose an approach which allows to define the Requirement Engineering step of a Cooperatif Information System. We used a notion of software engineering: the viewpoints. CIS is a complex system, it involves the cooperation of many stakeholders in a common purpose and each with their own viewpoint. This is why we used the notion of viewpoints, in order to decompose and partition the needs of a CIS according to the viewpoint of each stakeholder, to simplify its modeling. This approach define a metamodel of viewpoint that will allow us to instance the necessary viewpoint to define the needs and requirements of a CIS.
\end{abstract}

Keywords: viewpoints, needs analysis, requirements engineering, cooperatif information system.

\section{Introduction}

In a context of globalization of markets, companies of today face many challenges posed by: increased competition, the exceptional growth of services they must offer to their customers, the increased need to provide better quality of service and the necessity of cooperation and collaboration with other business partners to stay competitive in their activity domain and operating in socio-economic environments characterized by dynamism and increased turbulence.

Thus, a company can no longer be content with a closed information system, which would cause it to be unable to exchange information with its collaborators and partners. The Cooperatif Information System (CIS) area allows to support the intercompany relations in order to improve interactions and communication between partners. The size and complexity of these cooperatif information systems is therefore growing, their complexity makes their design more difficult. It is so very important to understand the needs and requirements of the system, which leads us to interest and define the first step of development of a CIS, ie the step of Requirements Engineering. The methods that exist in the domain of RE in software engineering does not allow to address the complex needs of a CIS which involves the cooperation of many stakeholders in a common purpose and each with their own viewpoint. To minimize this complexity we proposed an approach that incorporates a notion of 
software engineering which is the viewpoints from the RE step. It will allow us to decompose the needs of a CIS according to the viewpoint of each stakeholder. We called our approach: VpCIs (Viewpoints for Cooperatif Information System), it is a viewpoint's meta-model, it defines the necessary viewpoints that will allow us to define the needs of a CIS. To set this meta-model we have proposed a framework of 5 essential dimensions to describe a CIS. In what follows we present our motivations for the use of viewpoints in CIS, we then propose the VpCIs approach, we compare after that $\mathrm{VpCIs}$ with other approaches oriented viewpoints in RE domain and conclude we with our perspectives.

\section{Motivation}

$\mathrm{RE}$ is the first step of the life cycle development of every project[1], defining what the stakeholders (users, customers, suppliers, developers, businesses ) in a potential new system need from it, and also what the system must do in order to satisfy that need.

The RE process includes the elicitation phases, analysis, specification, validation and management of requirements [8]. We need to find a set of requirements that reflect the needs of these stakeholders. It will be necessary to determine who does what, on what, when, after what and before what, we must define the systems actors and relations or actions that may exist between them. System modeling supports the analysis and design process by introducing a degree of formality into the way systems are defined. Modeling provides a way of formalizing these representations, by not only defining a standard syntax, but also providing a medium for understanding and communicating the ideas associated with system development. So RE can be represented by using for example diagrams like data flow diagrams, EntityRelationship Diagrams, Statecharts, Object-Oriented Approaches(class diagram, use case), in our case we choose the diagrams (use case diagram). A method is a degree more prescriptive than a modeling approach, it tells us what to do to and in what order to do it. Methods use various representations ranging from natural language, through diagrammatic forms to formal mathematics like: viewpoints methods, ObjectOriented Methods, Formal Methods [1]. as we focus on methods oriented viewpoint, we talk about it in the following:

viewpoints methods : A viewpoint-based approach to requirements engineering recognizes that all information about the system requirements cannot be discovered by considering the system from a single perspective. Rather, we need to collect and organize requirements from a number of different viewpoints. A viewpoint is an encapsulation of partial information about a systems requirements. Information from different viewpoints must be integrated to form the final system specification [2]. there is several viewpoints methods in RE like : SADT [3],[4] CORE [5], VOSE [6], [7], VORD [8], [9], [10], [11], PreView [12].

We chose to use the viewpoints in the RE step of cooperatif information systems, being complex systems, the viewpoints can decompose system requirements and minimize the complexity, also for these arguments :

- Systems usage is heterogeneous there is no such thing as a typical user. 
Viewpoints may organize system requirements from different classes of system end-user and other system stakeholders.

- Different types of information are needed to specify systems including information about the application domain, information about the systems environment and engineering information about the systems development. Viewpoints may be used to collect and classify this information.

- Viewpoints may be used as a means of structuring the process of requirements elicitation. [2]

Given the complexity of CIS, modeling is done by splitting the system into several independent sub-models to avoid the design of a large system. This leads to management problems of coherence between these partial models, because they are never independent, since they contain information often functionally related. Objectoriented methods cannot therefore be as such to solve the problems of inconsistency between the partial models. [13] That is why we have chosen to integrate the viewpoints which will therefore allow us to decompose the system into several partial models. We propose in following our VpCIS approach oriented viewpoint, we believe that this approach is suitable for CIS.

\section{VpCIS Approach}

We work along the axis level modeling M2, M1, M0; we begin with the M2 level where we propose a meta-model of viewpoints representation in 5 dimensions for a CIS, we pass next to the M1 phase where we instantiate viewpoints from the metamodel which can be applied to an example in the M0 level.

\subsection{Viewpoint referential for a CIS}

We propose in what follows a viewpoint referential of 5 dimensions that we consider fundamental to describe a CIS viewpoint, we will describe later an explicit metamodel representation of viewpoint that will allow us to define our viewpoint in order to describe our system:

Level of description: defines at what phase of the life cycle of development is situated the VpCIS approach (analysis, specification, high-level design, design, code), in our case we are interested in the analysis needs phase.

Domain: the approach concerns a domain which can be generic, or focused on the business application or on a specific area of business. In our case we'll choose a generic domain which is CIS, we will after study an example and there so we move to business application.

Expression mode : the scheme and notation by which the viewpoint expresses what it can see (representation of RE), it can be text, graphics, diagram or using a formalism. In our case we chose to use graphics and diagrams (use case diagram).

Level modeling: the approach may be in one of the four layers of the architecture modeling:

- $\quad$ M3, the meta-meta-model such as MOF (self-descriptive layer); 
- $\quad$ M2 the meta-models such as UML;

- M1, the models such as the class diagram;

- M0, the real world (case study);

The VpCIS approach in this case (VpCIS meta-model) is in the M2 layer.

For reuse process/ By reuse process: the VpCIS approach can be by reuse (using viewpoints already defined) or for reuse (creating its own definition viewpoints), in our case we propose a meta-model for reuse but we can have to use viewpoints by reuse.

These dimensions are shown in the following figure 1.

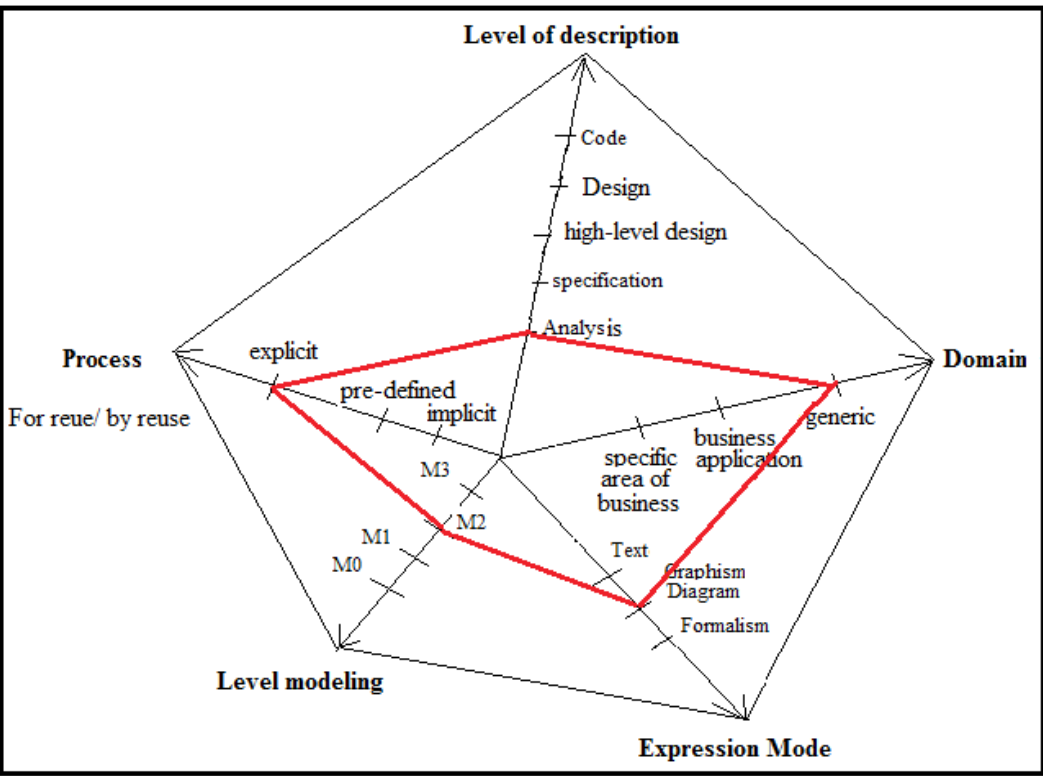

Fig. 1. shows 5 Dimensions of a meta-model of viewpoint (VpCIS)

\subsection{An explicit meta-model representation of a viewpoint}

We then propose an explicit meta-model representation of a viewpoint using the dimensions just mentioned as shown in Figure 2, this explicit representation will also enable other developers to define their own viewpoints.

We explain the details of the figure 2 in following, a viewpoint meta-model has these attributes :

Viewpoint type: We have two types of VP: Actor VP and Activity (action) VP, and as we choose use case diagram like expression mode, we then deduce two types of actor (primary and secondary) and so two types of action (primary and secondary).

Name: the name of the viewpoint (if it is a viewpoint actor it will be the actor's name. Goal: The aim and purpose of the viewpoint (for example, what should do the actor).

Level of description: in our case we said we are situated in the analysis phase which 


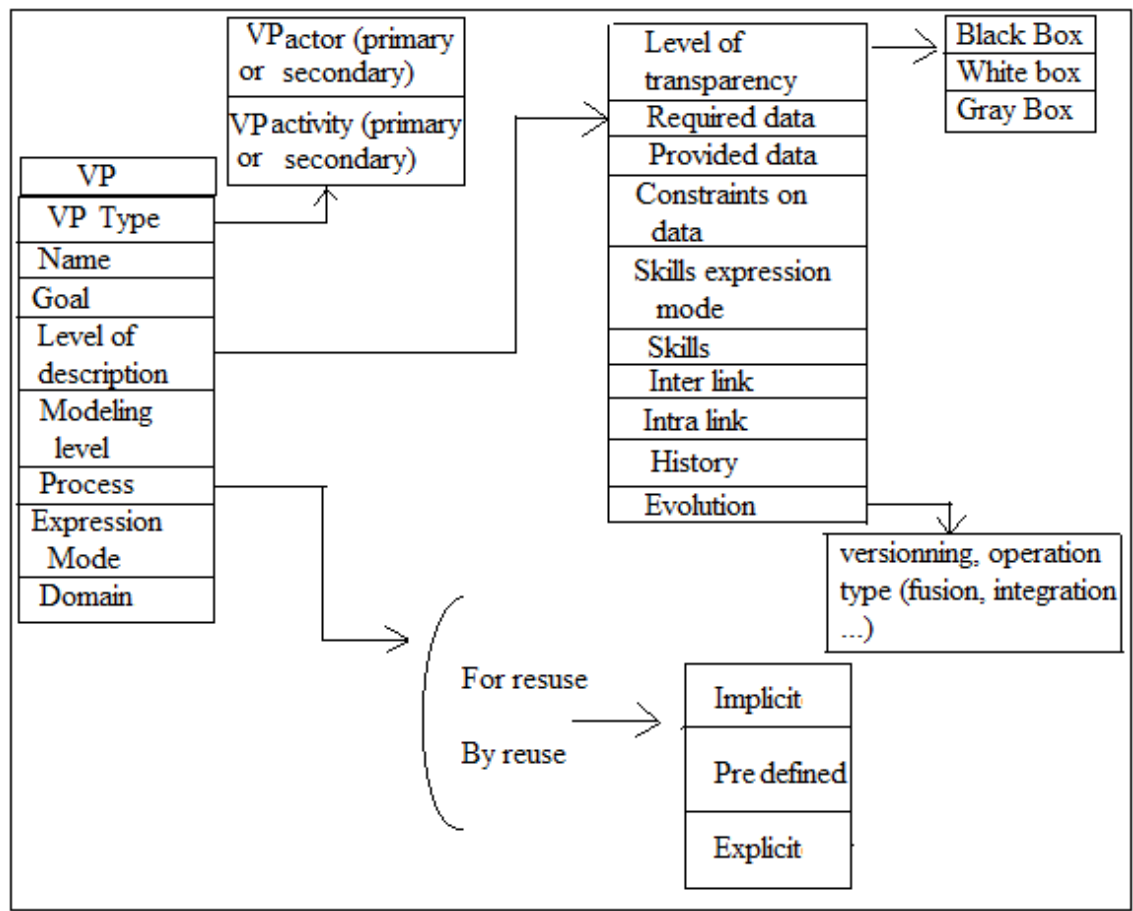

Fig. 2. Shows an explicit meta-model representation of a viewpoint (VpCIS)

- Level of transparency: can be: Black Box (we don't know about the viewpoint attributes), White Box (we can see the viewpoint attributes and even modify them), Gray Box (we can see the attributes but can't change them) in our case it is White Box.

- Required data: input information needed by the VP to accomplish its action or goal: functional requirements.

- Provided data: output information provided from the VP accomplishing his goal.

- Constraints on data: defines the non-functional requirements.

- Skills expression mode: the skills can be described textually or using a formalism or diagram as the activity diagram.

- Skills: the VP skills: description of its business and job.

- Inter Link: the links that may exist between different VP of various organizations.

- Intra link: links that may exist between different VP from the same organization.

- History: Historical actions.

- Evolution : the possible evolution of a VP (fusion, integration ...).

Modeling level: in our case we said that it is the level M2.

Process: the construction process can be implicit, explicit or pre-defined, in our 
case it is explicit.

Expression mode : we choose graphics and diagrams ( use case diagram).

Domain: we chose a generic domain: CIS.

This explicit description will allow us now to instantiate the viewpoints of the M1 level required to describe the needs of a CIS.

\subsection{VpCIS Viewpoints definition in M1 level}

At the level M2 we choose as expression mode the use case diagram, as it is characterized by the notion of actors and relations between them, we deduced then two types of viewpoints : viewpoints to define the actors of the cooperation and viewpoints to define the relations (actions) between them. In a use case diagram we have two types of actors : primary and secondary actors. We therefore define two types of VP actors (primary and secondary), we also have therefore deducted two types of actions: primary and secondary action. In what follows we show the viewpoints actor and action at M1 level modeling, the dimension modeling level consists in the meta-model of a set of attributes that will be used depending on the type of viewpoint.

The following Table 1 shows a primary actor viewpoint.

Table 1. Primary Actor Viewpoint

\begin{tabular}{|c|c|}
\hline Attributs & Description \\
\hline Type & Primary Actor. \\
\hline Name & Name of the Actor. \\
\hline Goal & What have to do the Actor. \\
\hline Skills expression mode & Skills expression mode of the actor like an activity diagram or text. \\
\hline Skills & $\begin{array}{l}\text { Description of the actor's job (primary actor will also delegate certain } \\
\text { actions or will have to be in contact with others to accomplish its } \\
\text { task, so we will list these actions). }\end{array}$ \\
\hline Intra Link & $\begin{array}{l}\text { The actor has links with other actors from the same organization } \\
\text { where he works. }\end{array}$ \\
\hline Inter Link & $\begin{array}{l}\text { The actor has links with other external actors from other } \\
\text { organizations. }\end{array}$ \\
\hline $\begin{array}{l}\text { Required data: } \\
\text { (functional } \\
\text { requirements) }\end{array}$ & $\begin{array}{l}\text { Requirement that can have the actor and information needed to } \\
\text { accomplish his actions. }\end{array}$ \\
\hline $\begin{array}{l}\text { Constraints on data } \\
\text { (non-functional } \\
\text { requirements) }\end{array}$ & non-functional requirements that can have the actor. \\
\hline Provided data & output information provided from the VP accomplishing his goal. \\
\hline History & When start the actions and when finish. \\
\hline
\end{tabular}


The following table 2 represents a secondary actor viewpoint.

Table 2. Secondary Actor Viewpoint

\begin{tabular}{ll}
\hline Attributs & Description \\
\hline Type & Secondary actor. \\
Name & Name of the Actor. \\
Goal & What have to do the Actor. \\
Skills expression mode & Skills expression mode of the actor like an activity diagram or text. \\
Skills & Description of the actor's job \\
Intra Link & The primary actors with he has relations. \\
Required data: & Requirements which can have the primary actor who delegated him \\
(functional & this action or asked him to do it and the information needed to \\
requirements) & accomplish the actions. \\
$\begin{array}{l}\text { Constraints on data } \\
\text { (non-functional }\end{array}$ & non-functional requirements that can have the primary actor. \\
requirements) & \\
Provided data & output information provided from the VP accomplishing his goal. \\
History & When start the actions and when finish. \\
\hline
\end{tabular}

The following table 3 represents an activity (action) viewpoint.

Table 3. Activity (Action) Viewpoint

\begin{tabular}{|c|c|}
\hline Attributs & Description \\
\hline Type & Primary or secondary. \\
\hline Name & the title of the action that connects two actors. \\
\hline Goal & What have to do the Actor. \\
\hline Skills expression mode & Skills expression mode of the action. \\
\hline Skills & Description of the activity. \\
\hline Inter or Intra Link & $\begin{array}{l}\text { Inter or Intra link between the actors, we deduce then two } \\
\text { attributes:(done by and asked by). }\end{array}$ \\
\hline -Done by & actor by which this action will be done \\
\hline -Asked by & the actor who asked to accomplish the task. \\
\hline $\begin{array}{l}\text { Required data: } \\
\text { (functional } \\
\text { requirements) }\end{array}$ & the different requirements needed to accomplish the action \\
\hline $\begin{array}{l}\text { Constraints on data } \\
\text { (non-functional } \\
\text { requirements) }\end{array}$ & Non-functional requirements to accomplish the action. \\
\hline History & When start the action and when finish. \\
\hline
\end{tabular}

\section{Comparison and analysis of VpCIS with other approaches}

The following table 4 shows a comparison between the methods oriented viewpoints : VpCIS, VORD, SADT, CORE, VOSE, PreView, MAMIE [14], taking into account the dimensions that we have cited, we note that VpCIs encompasses most of the 
methods such as VORD, which has been used in different articles like in [9], [10], [11], this is why we propose also a comparison between VpCIS.

Table 4. Comparison between methods oriented viewpoints

\begin{tabular}{|c|c|c|c|c|c|c|c|}
\hline & SADT & CORE & VOSE & VORD & PreView & MAMIE & VpCIS \\
\hline $\begin{array}{l}\text { Level of } \\
\text { descripti } \\
\text { on }\end{array}$ & Analysis & Analysis & Analysis & Analysis & Analysis & Analysis & Analysis \\
\hline Domain & $\begin{array}{l}\text { Generic } \\
\text { (No } \\
\text { explicit) }\end{array}$ & $\begin{array}{l}\text { Busines } \\
\text { s } \\
\text { applicati } \\
\text { on real } \\
\text { time } \\
\text { system) }\end{array}$ & $\begin{array}{l}\text { Generic } \\
\text { (compos } \\
\text { ite } \\
\text { system) }\end{array}$ & $\begin{array}{l}\text { Busines } \\
\text { s } \\
\text { applicati } \\
\text { on } \\
\text { (System } \\
\text { oriented } \\
\text { service) }\end{array}$ & $\begin{array}{l}\text { Busines } \\
\text { s } \\
\text { applicati } \\
\text { on } \\
\text { (projet } \\
\text { REAIM } \\
\text { S but } \\
\text { can be } \\
\text { generic) }\end{array}$ & $\begin{array}{l}\text { Generic } \\
\text { (coopera } \\
\text { tif } \\
\text { informat } \\
\text { ion } \\
\text { system) }\end{array}$ & $\begin{array}{l}\text { Generic } \\
\text { (coopera } \\
\text { tif } \\
\text { informat } \\
\text { ion } \\
\text { system) }\end{array}$ \\
\hline $\begin{array}{l}\text { Expressi } \\
\text { on mode }\end{array}$ & $\begin{array}{l}\text { Graphe/ } \\
\text { diag }\end{array}$ & $\begin{array}{l}\text { Graphe/ } \\
\text { diag }\end{array}$ & $\begin{array}{l}\text { Graphe/ } \\
\text { diag }\end{array}$ & $\begin{array}{l}\text { Graphe/ } \\
\text { diag }\end{array}$ & $\begin{array}{l}\text { Graphe/ } \\
\text { diag }\end{array}$ & $\begin{array}{l}\text { Graphe/ } \\
\text { diag }\end{array}$ & $\begin{array}{l}\text { Graphe/ } \\
\text { diag }\end{array}$ \\
\hline $\begin{array}{l}\text { Level } \\
\text { modeling }\end{array}$ & M1 & M1 & M1 & M1 & M1 & M1 & M1, M2 \\
\hline Process & Implicit & Explicit & Explicit & $\begin{array}{l}\text { Pre- } \\
\text { defined }\end{array}$ & Explicit & $\begin{array}{l}\text { Pre- } \\
\text { defined }\end{array}$ & Explicit \\
\hline
\end{tabular}

The following figure 3 shows a comparison between VpCIs and VORD, we note that VpCIs includes VORD method.

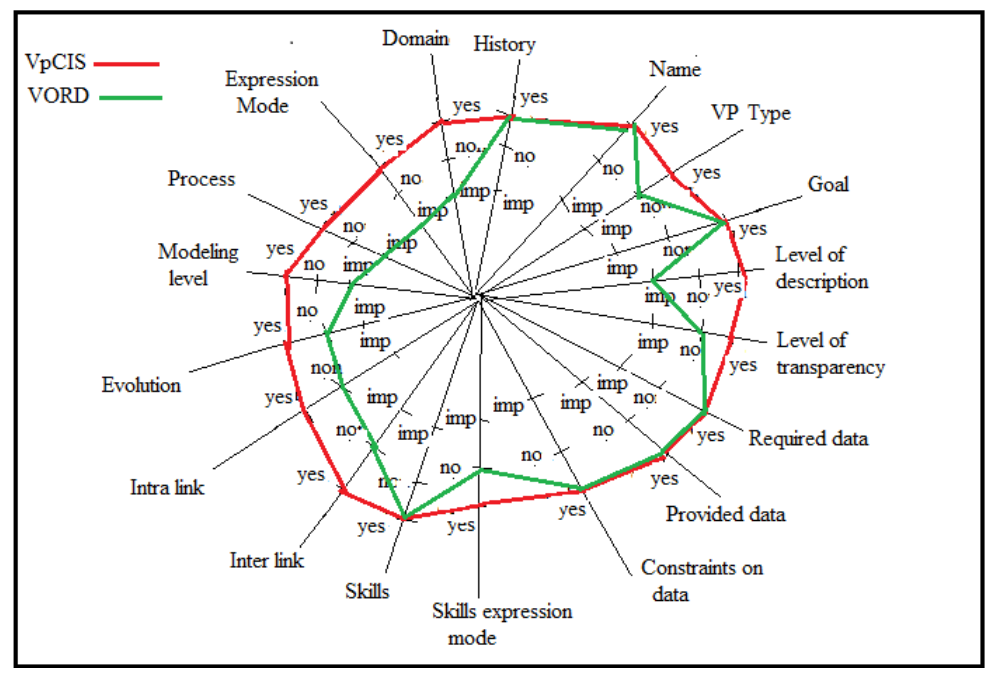

Fig. 3. shows a comparison between VpCIS and VORD 


\section{Case study}

We pass now to the level modeling M0 where we apply the viewpoints of the level M1 to a case study. Several examples have used the method VORD such as in the article[9][10][11], We choose one of them : [10]. The viewpoint domain is now : business application: MCS. Medical Care System (MCS) is an attempt to provide the awareness of the First- Aid to the community in an easy, cheap and rapid way, at their door steps. People can interact with the system, simply by connecting with the internet and the system will show them First-Aid procedures for different situations that required medical treatment. The paramedic connect on the system to find the first aid to provide it to the victim, if he has difficulties he contact the hospital staff to explain him how to use the system or to make him in contact with a specialist doctor, the hospital staff can also contact the system administrator to maintain the system.

The figure 4 following shows the use case diagram of the system

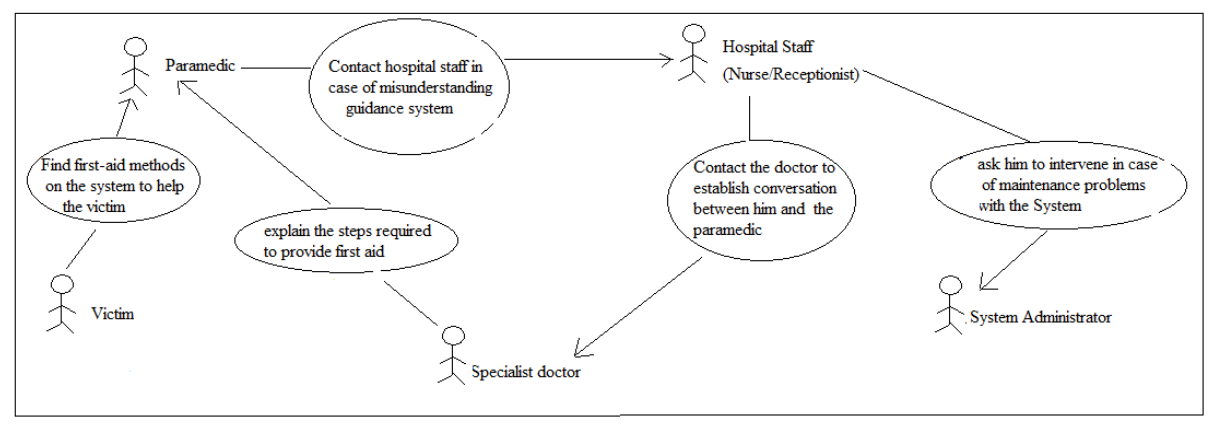

Fig. 4. shows the use case diagram of MCS

Once we have indentified the actors and the actions that rely them in the use case, we pass now to the definition of the viewpoints:

The primary actors VP are : Paramedic, Hospital Staff, Specialist doctor

The secondary actor VP is : System Administrator

The primary actions VP: Find first-aid methods, contact the hospital staff in case of problems, contact the specialist doctor, explain the steps required to provide first-aid The secondary actions VP : contact the system administrator to maintain the system Let's take an example of viewpoint : the specialist doctor viewpoint :

Type : primary

Name : Adam

Goal : assist the paramedic and explain the procedure to follow

Skills expression mode : textual

Skills : he is responsible for the medical treatment of any sudden case, or to provide online help to any first aid provider.

Required data : describe how is the victim and details of the accident

Provided data: the first-aid method

Constraints on data : the information about the victim must be detailed.

Intra link: hospital staff

Inter link : paramedic 
History :receive the call from the hospital staff, be in contact with the paramedic and explain the steps to follow in order to give first aid to the victim

\section{Conclusion}

In this article we discussed our motivation for the use of viewpoints in the RE step of a CIS, We proposed after that an approach which define a viewpoint meta-model the analysis needs phase of a CIS : VpCIS. We choose the use case diagram like expression mode to instance VpCIS to define the actors and the relations between them, we expect to develop a tool which allows to support the VpCIS approach and develop a CIS using this definition of the viewpoints from the analysis needs phase.

\section{References}

1. Elizabeth Hull, Kes Jackson, Jeremy Dick.: Requirements Engineering. third edition, springer.2010.

2. Ian Sommerville and Pete Sawyer. Viewpoints: Principles, Problems and a Practical Approach to Requirements Engineering, Annals of Software Engineering 3 (1997) 101, 130

3. Ross, D. and Schoman, K. Structured Analysis for Requirements Definition, IEEE Transactions on Software Engineering 3(1), January 1977.

4. Mylopoulos J. Conceptual modeling iii. structured analysis and design technique(sadt). (2004).

5. Mullery, G. CORE -A method for controlled requirements specification. Fourth International Conference on Software Engineering. (1979). Munich, RFA:126, 135. IEEE.

6. A. Finkelsetin J. Kramer B. Nuseibeh L. Finkelstein M. Goedicke Viewpoints: A Framework for Integrating Multiple Perspectives in System Development, International Journal of Software Engineering and Knowledge Engineering 2(1):31, 58, March 1992,

7. Mehrdad Sabetzade, Anthony Finkelstein, Michael Goedicke Viewpoints, in Encyclopedia of Software Engineering, P. Laplante, Ed. New York: Taylor and Francis, 2010.

8. Kotonya et Sommerville. Requirements Engineering : Process and Techniques, John Wiley and Son, Great Britain, 1998.

9. Ahmed M. Salem. Requirements Analysis through Viewpoints Oriented Requirements Model (VORD), (IJACSA) International Journal of Advanced Computer Science and Applications, Vol. 1, No. 5, November 2010.

10. Fiaz Ahmad, Mohamed Osama Khozium. Medical Care System Using VORD, Methodology, Ubiquitous Computing and Communication Journal, http://dec.bournemouth.ac.uk/sta_/kphalp/rebnita05.pdf

11. Md. Faisal, Mohammed Hussain. Emphasizing Requirement Elicitation Process for Electronic Payment Secured System using VORD Methodology - A Practical Approach.2012

12. I. Sommerville, P. Sawyer, S.Viller. Viewpoints for requirements elicitation: a practical approach, IEEE International Conference on Requirements Engineering, Colorado Springs, USA, April 6-10, 1998.

13. Mahmoud NASSAR. Analyse/conception par points de vue : le profil VUML, INSTITUT NATIONAL POLYTECHNIQUE DE TOULOUSE, 2005.

14. Hakim BENDJENNA . Ingénierie des Exigences pour les Processus Inter organisationnels, l'Université Mentouri de Constantine et de l'Université de Toulouse. 2010. 